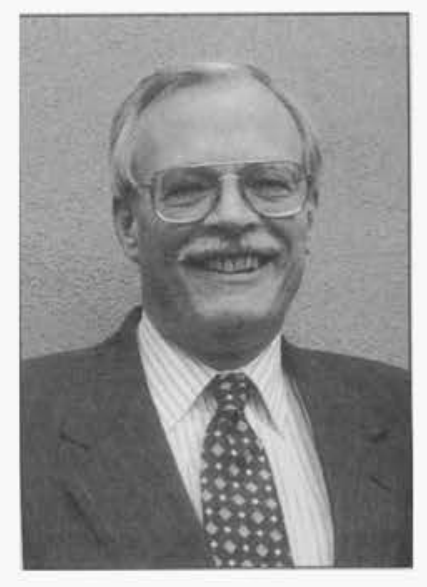

\title{
California-Catalonia connection enriches research
}

HENRY J. VAUX, Jr. Associate Vice President for Programs Agriculture and Natural Resources

I n 1986 a group of UC faculty and administrators, Califor1 nia political representatives and business leaders journeyed to Barcelona, Spain, to join counterparts from the Autonomous Province of Catalonia in acknowledging the $200^{\text {th }}$ anniversary of the death of Gaspar de Portola. A renowned Spanish explorer with roots in a remote Catalonian valley in the Pyrenees, Gaspar de Portola was sent to secure California for Spain and ultimately became the first Governor of California.

The purpose of the 1986 occasion was to create a sister state relationship between California and Catalonia. There have been some far-reaching consequences of that effort. In 1988 then Vice President Kenneth Farrell signed a Memorandum of Understanding with the Counselor of Agriculture of Catalonia which called for UC researchers in a variety of disciplines to work collaboratively with researchers from the Catalonian Institute for Research on Agricultural Technology (IRTA).

Since 1988 research and extension faculty from DANR have participated with colleagues from IRTA on a variety of projects. While some of the projects are focused on formal collaborative work, individual faculty initiatives have always been encouraged. The leadership of DANR and IRTA has recognized the importance of developing personal relationships between the investigators and has fostered the development of these relationships through sponsored exchanges.

Much of the more formal collaborative work has been in the area of pest management and there has been a joint project on the management of wildfire. The largest and most sustained collaboration has focused on deficit irrigation of tree crops. This project has been ongoing for more than 10 years, and has involved between 30 and 40 collaborators, including faculty from other Spanish institutions, although the core group of researchers is somewhat smaller.

Collaborating faculty on the deficit irrigation project meet every year with meeting locations alternating between California and Catalonia. In 1996 the core collaborators spent 3 weeks together at the Kearney Agricultural Center working on experiments with uniquely instrumented peach trees.

Some of the results of that work are reported in two articles, which appear in this edition of California Agriculture. The collaborative work suggests that there are only small margins of error in management of orchards irrigated with $\mathrm{drip} /$ microsprinkler systems. The collaborators also report on a new and superior method for measuring the moisture status of trees. This method is more sensitive than current plant-based stress indicators and holds considerable promise as a tool for improving orchard water management. Over time, these results should be very helpful to tree fruit growers in both California and Spain.

What the articles may not reveal so clearly is how the quality and depth of the underlying science has been expanded as a consequence of the collaboration. The perspective from which science is conducted is often an important determinant of the quality and richness of the work that results.

A unique feature of the collaboration of UC and IRTA scientists on deficit irrigation stems from the distinctly different perspectives which each brings to their work. In California, drought occurs on the average of once every 7 years. And, statistically, water deliveries to agriculture may be curtailed to some extent in as many as 2 additional years in each 7. For the California grower, successful management of permanent crops in a typical water short situation requires some knowledge of the optimal way to spread deficits in available irrigation water of perhaps $15 \%$ to $30 \%$ over the annual growing cycle of the tree. The Catalonian grower, on the other hand, is faced with circumstances in which irrigation water is available in most years to meet only $25 \%$ to $35 \%$ of crop evapotranspiration. The problem of the Catalonia grower is to know when the application of these slim water rations can make the most difference in crop yield.

Although the applied research approaches taken by Californians and Catalonians are tailored to the specific problems of their respective regions, their collaboration has led to a richer and more comprehensive understanding of the physiology of tree response to moisture stress than would have emerged from the work of either group alone.

The California-Catalonia connection is an excellent example of how researchers working on similar problems in different parts of the world can collaborate to develop more comprehensive and richer research results that then benefit the growers in each region. The leaders of DANR and IRTA will continue to foster opportunities that offer the promise of enhanced pay-offs to growers. 